\title{
Low antigenicity of hematopoietic progenitor cells derived from human ES cells
}

This article was published in the following Dove Press journal:

Transplant Research and Risk Management

30 January 2010

Number of times this article has been viewed

\author{
Eun-Mi Kim' \\ Nicholas Zavazava ${ }^{1,2}$ \\ 'Department of Internal Medicine, \\ University of lowa and Veterans \\ Affairs Medical Center, lowa City, \\ lowa, USA; ${ }^{2}$ Immunology Graduate \\ Program, University of lowa, lowa \\ City, lowa, USA
}

\begin{abstract}
Human embryonic stem (hES) cells are essential for improved understanding of diseases and our ability to probe new therapies for use in humans. Currently, bone marrow cells and cord blood cells are used for transplantation into patients with hematopoietic malignancies, immunodeficiencies and in some cases for the treatment of autoimmune diseases. However, due to the high immunogenicity of these hematopoietic cells, toxic regimens of drugs are required for preconditioning and prevention of rejection. Here, we investigated the efficiency of deriving hematopoietic progenitor cells (HPCs) from the hES cell line H13, after co-culturing with the murine stromal cell line OP9. We show that HPCs derived from the H13 ES cells poorly express major histocompatibility complex (MHC) class I and no detectable class II antigens (HLA-DR). These characteristics make hES cell-derived hematopoietic cells (HPCs) ideal candidates for transplantation across MHC barriers under minimal immunosuppression.
\end{abstract}

Keywords: human embryonic stem cells, H13, hematopoiesis, OP9 stromal cells, immunogenicity

\section{Introduction}

Embryonic stem (ES) cells are generated from the inner cell mass of the blastocyst and are capable of developing into tissues of all three germ layers. ${ }^{1}$ In vitro, differentiation of ES cells into different cells and tissues including hematopoietic cells and cardiomyocytes have been studied. However, establishing high yields of these progenitors cells remains a challenge. ${ }^{2,3}$ Nonetheless, human ES cells (hES cells) provide opportunities for establishing new cellular therapies that might become applicable in human diseases. ${ }^{2}$ The major advantage of ES-cell derived pluripotent cells is that they are less immunogenic than the traditional sources of hematopoietic cells. Studies from our lab show that mouse-derived hematopoietic progenitor cells can engraft in major histocompatibility complex (MHC) disparate recipients. ${ }^{4}$ At the time of transplantation, the hematopoietic cells (HPCs) poorly expressed class I antigens but no class II molecules. However, post transplantation, we observed that there was a gradual increase in both class I and class II antigens. MHC expression on these cells was comparable to that of bone marrow cells by day 60 post-transplantation. We surmised that the period before MHC normalization is a "window of opportunity" for engrafting donor-specific allografts. Indeed we exploited this property and were able to induce tolerance to donor-type cardiac allografts. ${ }^{5}$ Thus, establishing protocols for the successful differentiation of human ES cells into hematopoietic progenitors might open up opportunities for the generation of hematopoietic cells that could be used in establishing mixed chimerism in humans without the need for severe immunosuppressive regimens.
Correspondence: Nicholas Zavazava University of lowa Hospitals and Clinics, Department of Internal Medicine, 200 Hawkins Drive, C5I-F, lowa City, lowa 52242, USA

Tel +I 3193846577

Fax +I 3193568280

Email nicholas-zavazava@uiowa.edu 
A major hurdle to successful differentiation of hES cells is that we understand very little about the transcriptional regulation of hematopoiesis in these cells. This impacts the number of cells we can derive from these ES cells. In general, the yield reported in most protocols is very low..$^{6-8}$ These protocols have relied on the co-culture of hESCs with stromal cell lines S17, OP9 and fetal liver derived stromal cells. ${ }^{9-12}$ However, to be able to study the immunobiology of ES-derived HPCs, we need much higher yields of cells. More recently, Lako et al reported on an alternative approach to deriving HPCs. They used aorta gonado mesonephros (AGM)-derived cell lines. ${ }^{13}$ In those experiments, they were able to increase the differentiation efficiency and engraftment of these ES-derived HPCs into immunocompromised NOD/ LtSz-Scid IL2R $\gamma^{\text {null }}$ recipient mice. Although this appears to be a more preferred approach, further work needs to be done to improve on the yield of progenitor cells.

Some groups established that ectopic expression of HOXB4 can mediate a significant expansion of ES cellderived progenitors in vitro and in vivo. ${ }^{14-17}$ These data were, however, established in mice models. In contrast, ectopic expression of HOXB4 in human ES cell-derived progenitored had no effect on the repopulating capacity of human ES cell-derived progenitors. ${ }^{18}$

Here, we differentiated the established human cell line H13, into HPCs in vitro. Our results show that human ES cellderived hematopoietic progenitor cells express $\mathrm{CD} 34^{+}, \mathrm{CD} 43^{+}$ and low levels of MHC class I antigens, but no class II antigens. This characteristic is similar to that observed in mouse cells. Thus, there is reason to be optimistic that hES cells might engraft in the allogenic setting, without the need for severe preconditioning regimens, an ideal situation for creating mixed chimerism that could lead to transplantation tolerance.

\section{Materials and methods}

\section{ES cell lines and culture conditions}

The human ES cell line H13 was purchased from WiCell, Wisconsin, and maintained in DMEM/F12 (Dulbecco's modified eagle medium; GIBCO ${ }^{\circledR} / \mathrm{BRL}$, Carlsbad, CA, USA) containing 20\% Knockout $^{\mathrm{TM}}$ Serum Replacement (Invitrogen, Carlsbad, CA, USA), $10 \mathrm{ng} / \mathrm{mL}$ bFGF (basic fibroblast growth factor; Invitrogen, Carlsbad, CA, USA), 1 mM GlutaMax ${ }^{\mathrm{TM}}$ (Invitrogen, Carlsbad, CA, USA), $100 \mu \mathrm{M}$ nonessential amino acids, $100 \mu \mathrm{M}$ 2-mercaptoethanol, $50 \mathrm{U} / \mathrm{mL}$ penicillin and $50 \mu \mathrm{g} / \mathrm{mL}$ streptomycin. The culture medium was changed daily, and the cells passaged every 5 to 6 days to avoid differentiation. The stromal cell line OP9 (a gift from Dr ZunigaPflucker University of Toronto, Canada), were cultured in $\alpha$-MEM (minimum essential medium; $\mathrm{GIBCO}^{\circledR} / \mathrm{BRL}$, Carlsbad, CA, USA) supplemented with $20 \%$ fetal calf serum (FCS), $100 \mathrm{U} / \mathrm{mL}$ penicillin, $100 \mu \mathrm{g} / \mathrm{mL}$ streptomycin $\left(\mathrm{GIBCO}^{\circledR} / \mathrm{BRL}, \mathrm{Carlsbad}, \mathrm{CA}\right.$, USA). Cells that were passaged 35 to 56 times were used in this study.

\section{Immunofluorescence staining}

The phenotyping of the cells was performed using immunostaining. H13 cells grown on feeder cells were fixed in $4 \%$ paraformaldehyde for $30 \mathrm{~min}$, washed with PBS, permeablized with $0.1 \%$ Triton X-100 for 30 min and blocked in $3 \%$ BSA in PBS for $2 \mathrm{~h}$. After washing with PBS, the cells were incubated with Alexa Fluor ${ }^{\circledR} 488$ mouse anti-human TRA 1-60, TRA 1-81 and Alexa Fluor ${ }^{\circledR} 488$ mouse antiSSEA-4 (Invitrogen, Carlsbad, CA, USA) for 1hour at room temperature and washed. Cells were incubated with OCT3/4 primary antibodies (1:50; Santa Cruze Biotechnology, CA, USA) overnight at $4{ }^{\circ} \mathrm{C}$, washed and incubated with an Alexa Fluor ${ }^{\circledR}$ 488-conjugated goat anti-mouse IgG (1:500; Molecular Probes ${ }^{\circledR}$, Eugene, OR, USA) secondary antibody for 1 hour and washed. Alkaline phosphatase staining was performed using the alkaline phosphatase kit (Stemgent, San Diego, CA, USA).

\section{Embryoid body formation}

Embryoid bodies (EBs) spontaneously develop if ES cells are left to differentiate. These EBs are critical for the derivation of many cell types and tissues from ES cells because they contain cells from all three germ layers. Further, the cell signaling within these EBs supports further differentiation of the cells. To form EBs, H13 cells were harvested using $1 \mathrm{mg} / \mathrm{mL}$ collagenase type IV (GIBCO ${ }^{\circledR} / \mathrm{BRL}$, Carlsbad, CA, USA) and cultured in low attachment plates in DMEM/F12 consisting of $20 \%$ knockout serum, $1 \mathrm{mM}$ GlutaMax $^{\mathrm{TM}}$, $100 \mu \mathrm{M}$ nonessential amino acids, $100 \mu \mathrm{M}$ 2-mercaptoethanol, $50 \mathrm{U} / \mathrm{mL}$ penicillin and $50 \mu \mathrm{g} / \mathrm{mL}$ streptomycin for 8-10 days.

\section{Reverse transcriptase-polymerase chain reaction (RT-PCR)}

To ascertain the expression of embryonic stem cell genes in the H13 ES cells, RT-PCR was performed. Briefly, total RNA was extracted using Trizol $^{\circledR}$ reagent $\left(\mathrm{GIBCO}^{\circledR} / \mathrm{BRL}\right.$, Carlsbad, CA, USA) according to the manufacturer's instructions. Aliquots $(3 \mu \mathrm{g})$ of total RNA were transcribed into cDNA at $37{ }^{\circ} \mathrm{C}$ for 1 hour in a total volume of $20 \mu 1$ with $2.5 \mathrm{U}$ of moloney murine leukemia virus reverse transcriptase (Roche, Mannheim, Germany). Reverse transcribed cDNA samples 
were added to a PCR (polymerase chain reaction) mixture consisting of 10x PCR buffer, $0.2 \mathrm{mM}$ dNTP, 0.5 U rTaq DNA polymerase (Invitrogen, Carlsbad, CA, USA) and 10 pmol of primers for each gene which are Oct4 (NM_002701), Sox2 (NM_0003106), c-myc (NM_002467), KLF4 (NM_004235), Nanog (NM_024865), REX1 (NM_172239), Dnmt3b (NM_ 006892), IL-7R $\alpha$ (NM_002185), GATA2 (NM_032638), HOX A9 (NM_152739), ATF4 (NM_001675), and $\beta$-actin (NM_001101). Table 1 shows the sequences of the primers used. All PCR mixtures were heated to $95{ }^{\circ} \mathrm{C}$ for 1 minute and cycled 30 times at $95{ }^{\circ} \mathrm{C}$ for $1 \mathrm{~min}, 55^{\circ} \mathrm{C}$ for 1 minute and $72{ }^{\circ} \mathrm{C}$ for 2 minutes, followed by an additional extension step at $72{ }^{\circ} \mathrm{C}$ for 10 minutes. PCR products were electrophoresed and visualized by ethidium bromide staining.

\section{Teratoma formation}

Teratoma formation is crucial in confirming whether cell cultures are pluripotent. For teratoma formation, H13 cells were washed with DMEM/F12 medium, the cells were injected subcutaneously into the dorsal flank of a SCID (severe combined immunodeficient) mouse. After 9 weeks, teratomas were dissected, washed with PBS (phosphate buffered saline) and fixed in $4 \%$ paraformaldehyde. Histological sections were assessed by HE (hematoxylin and eosin) staining of paraffin-embedded teratoma tissue.

\section{In vitro generation of ES cell-derived HPCs}

To differentiate $\mathrm{H} 13$ cells into $\mathrm{CD} 34^{+}$cells, we used the OP9 co-culture method. ${ }^{11}$ The undifferentiated H13 cells (one well of a 6 well plate) were incubated on overgrown OP9 cells in $10 \mathrm{~cm}$ culture dishes precoated with $0.1 \%$ gelatin (Sigma-Aldrich ${ }^{\circledR}$ St Louis, MO) in the differentiation media ( $\alpha$-MEM supplemented with $10 \%$ FBS, $100 \mathrm{U} / \mathrm{mL}$ penicillin, $100 \mu \mathrm{g} / \mathrm{mL}$ streptomycin, and $100 \mu \mathrm{M}$ MTG, and $50 \mu \mathrm{g} / \mathrm{mL}$ ascorbic acid) for 9-10 days. Half of culture medium was changed on days 4,6 and 8 .

\section{Flow cytometry}

To confirm whether the H13 derived hematopoietic progenitor cells express the hematopoietic cell markers, single cell suspensions of H13-derived cells were prepared using the cell disassociation buffer $\left(\mathrm{GIBCO}^{\circledR} / \mathrm{BRL}\right.$, Carlsbad, CA, USA) for 30 minutes at $37^{\circ} \mathrm{C}$, washed with PBS and stained with antibodies: Biotin-conjugated anti-human CD34 (BioLegend, San Diego, CA, USA), Alexa Fluor ${ }^{\circledR} 488$ mouse anti-human CD31 (BD PharMingen, San Diego, CA, USA) fluorescein isothiocyanate (FITC)-conjugated anti-human CD43 (BioLegend, San Diego, CA), phycoerythrin (PE)-conjugated anti-human HLA-DR (BD PharMingen, San Diego, CA), mAb W6/32 directed against conformed MHC-I proteins, secondary FITCanti mouse IgG2a (BD PharMingen, San Diego, CA). And flow cytometry was performed and data analyzed using Cellquest Software (Becton Dickinson, San Diego, CA). Prior to the flow cytometry, the stromal cells were removed by immunomagnetic cell sorting using the anti-CD29 antibody.

\section{Colony forming unit assay}

To confirm whether the $\mathrm{H} 13$ derived hematopoietic progenitor cells proliferate and differentiate into hematopoietic cells, H13 derived hematopoietic progenitor cells were purified using the CD34 MicroBead (Miltenyi Biotech, Bergisch Gladbach, Germany) kit. Cells were plated onto

Table I List of PCR primer sequences used

\begin{tabular}{|c|c|c|}
\hline Gene & Sense primer & Antisense primer \\
\hline Oct4 (NM_00270I) & 5'-GAGAACAATGAGAACCTTCAGGAGA-3' & 5'-TTCTGG CGC CGGTTACAGAACCA-3' \\
\hline Sox2 (NM_0003106) & 5'-AGGAGAACCCCAAGATGCAC-3' & 5'-TGTAGGTCTGCGAGCTGGTC-3' \\
\hline c-myc (NM_002A67) & 5'-GCGTCCTGGGAAGGGAGATCCGGAGC-3' & 5'-TTGAGGGGCATCGTCGCGGGAGGCTG-3' \\
\hline KLF4 (NM_004235) & 5'-ACGA TCGTGGCCCCGGAAAAGGACC-3' & 5'-TGATTGTAGTGCTTTCTGGCTGGGCTCC-3' \\
\hline Nanog (NM_024865) & 5'-AAGACAAGGTCCCGGTCAAG-3' & 5'-CCTAGTGGTCTGCT GTATTAC-3' \\
\hline REXI (NM_I72239) & 5'-C AG ATC CTAAAC AGCTCGC AG AAT-3' & 5'-GCGTACG C AAATTAAAAGTCC AG A-3' \\
\hline Dnmt3b (NM_006892) & 5'-TGCTGCTCACAGGGCCCGAT ACTTC-3' & 5'-TCCTTTCGAGCTCAGTGCACCACAAAAC-3' \\
\hline IL-7Ra (NM_002I85) & 5'-CTGTTGGTCATCTTGGCCTG-3' & 5'-AGGAGAGAATAGGGGCGTCA-3' \\
\hline GATA2 (NM_032638) & 5'-CCTCCAGCTTCACCCCTAAG-3' & 5'-GGGGATGACTTCTCCTGCAT-3' \\
\hline HOXA9 (NM_I52739) & 5'-TGCGGGCATTTAAGTCTGTC-3' & 5'-TCTACAGTAGCCCAATGGCG-3' \\
\hline ATF4 (NM_00I675) & 5'-AACAGCAAGGAGGATGCCTT-3' & 5'-GTGCTGAGGAGACCCCAGAT-3' \\
\hline$\beta$-actin (NM_00II0I) & 5'-GTGGGGCGCCCCAGGCACCA-3' & 5'-CTCCTTAATGTCACGCACGATTTC-3' \\
\hline
\end{tabular}


methylcellulose colony-forming assay media containing SCF, GM-CSF, IL-3, and Epo (R\&D system, Minneapolis, $\mathrm{MN}$ ) at a density of 25,000 cells $\mathrm{mL}^{-1}$. These cells were incubated at $37^{\circ} \mathrm{C}, 5 \% \mathrm{CO}_{2}$.

\section{Results}

\section{Characterization of human ES cells}

To characterize the undifferentiated human ES cells, we stained the cells for TRA-1-60, TRA-1-81, Oct4 and alkaline phosphatase. The H13 cells strongly expressed these pluripotent markers (Figure 1), suggesting that the cells are pluripotent. To further confirm the expression of other pluripotency genes, cDNA was prepared and RT-PCR performed. Our data show that $\mathrm{H} 13$ cells robustly express Oct4, Klf4, Sox2, c-myc, Nanog, REX-1 and Dnmt3b (Figure 2). This gene set is expressed in pluripotent cells, which were not expressed in fibroblasts that were used as controls. However, fibroblasts express Klf4, c-myc and Rex1.

\section{In vitro and in vivo differentiation of $\mathrm{HI} 3$ cells}

H13 cells were allowed to form embryoid bodies. Briefly, clumps of H13 cells were trypsinized with collagenase IV and cultured on ultra low attached plates for 8-10 days in the differentiation media without bFGF. Figure 3 a shows typical embryoid bodies, which appeared like ball-shaped structures on day 8. On day 10, RT-PCR was performed to confirm the expression of germ layer-specific genes of the endoderm, mesoderm and ectoderm. A set of genes characteristic of each germ layer was chosen and primers designed for RT-PCR. Our results show that the EBs consisted of differentiated cells which expressed GATA4 (endoderm marker), BRACHYURY and MSX1 (mesoderm markers), Nestin and Musashi (ectoderm markers).

To further confirm pluripotency of $\mathrm{H} 13$ cells in vivo, we injected $\mathrm{H} 13$ cells subcutaneously into the dorsal flanks of immunodeficient (SCID) mice. Nine weeks after injection, tumor formation was visible. Animals were sacrificed to recover the tumors for histological examination. HE staining showed various tissues including bone (mesoderm), endodermal tissue (endoderm) and epidermal (ectoderm), suggesting that the H13 cells are indeed pluripotent as they form tissues from all three germ layers, Figure 4.

\section{Differentiation of $\mathrm{HI} 3$ into hematopoietic progenitor cells}

Currently, the most efficient way to generate hematopoietic cells from ES cells is to co-culture them with stromal
Tra-1-81

a

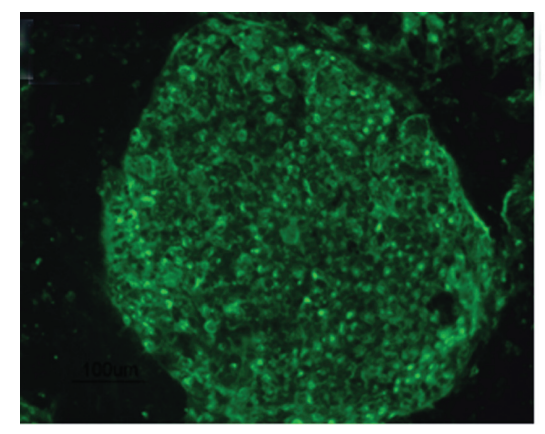

Oct4/DAPI

c

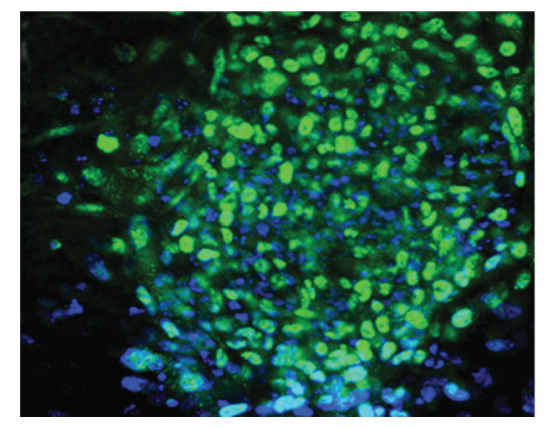

Tra-1-60

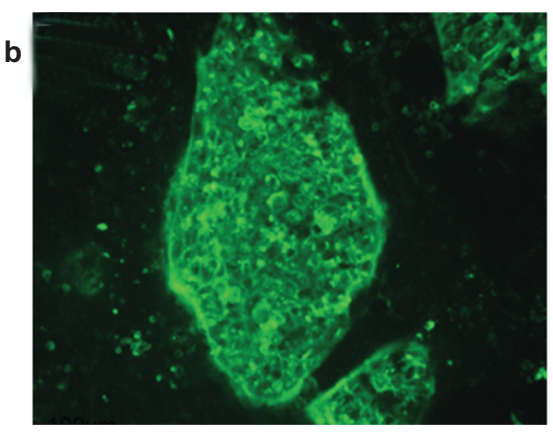

AP-1

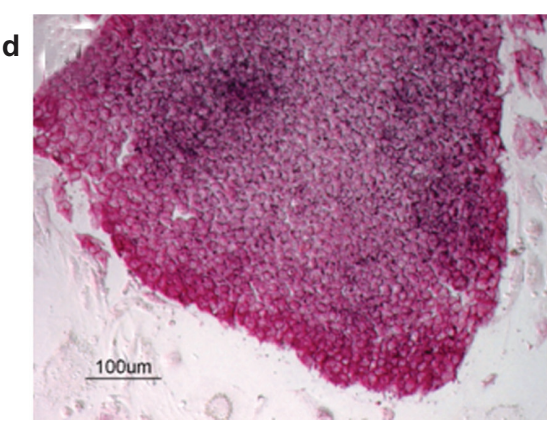

Figure I Phenotype of HI 3 ES cells: Representative immunofluorescence stains of the HI 3 cell line.The cells express Tra- I-60 (a), Tra- I-8I (b), oct4/DAPI (c) and alkaline phosphatase (d) confirming their non-differentiated state. 


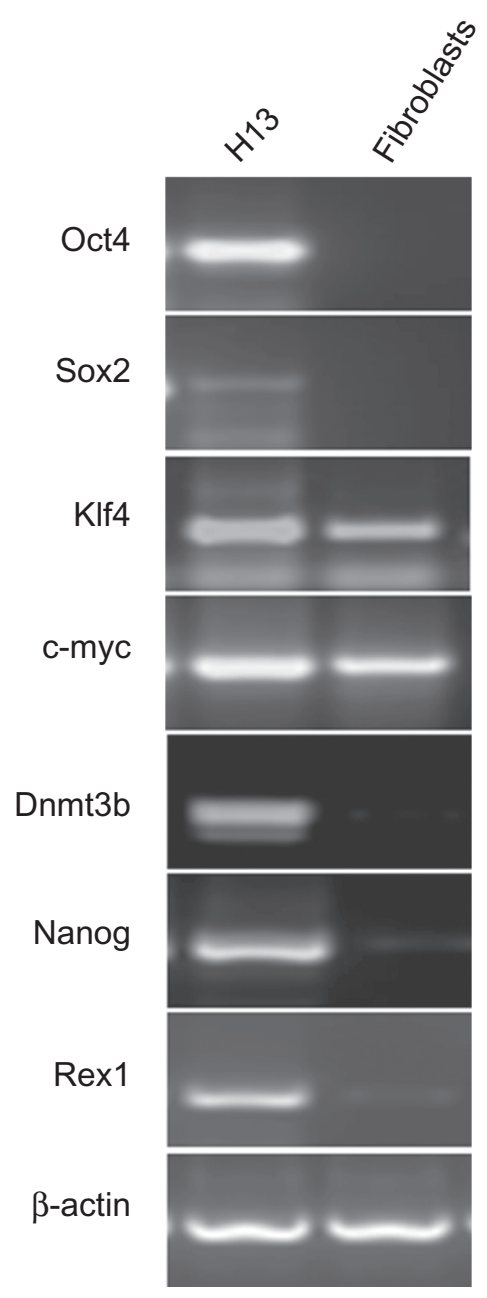

Figure $2 \mathrm{HI} 3$ cells express pluripotent genes: RNA was prepared from $\mathrm{HI} 3$ cells and fibroblasts and used for RT-PCR of ES cell-specific genes. Fibroblasts were used as controls. cell lines. For the most part the murine stromal cell line OP9 has been widely used. To generate hematopoietic cells from the H13 cell line, cells were co-cultured with the stromal cell line OP9. ${ }^{11}$ Briefly, undifferentiated H13 cells were maintained in culture on irradiated mouse feeder cells (Figure 5a). The cells were harvested using collagenase IV. The undifferentiated $\mathrm{H} 13$ cells were plated onto the overgrown OP9 cell plates and cultured for 9 days (Figure 5b). Typically, the H13 cells became spherical and no longer grew in cell clumps.

Hematopoietic progenitor cells can form hematopoietic colony forming units (CFU). ${ }^{10}$ To confirm CFU formation of these differentiated cells, we isolated $\mathrm{CD} 34^{+}$cell populations from differentiated cells using CD34 microbeads and plated 25,000 cells into methylcellulose media containing SCF, GM-CSF, IL-3 and Epo. Figure 5c shows BFU-E (burstforming unit-erythroid) and CFU-GM (colony-forming unit-granulocyte/macrophage) on day 18 . These data show that these differentiated cells have hematopoietic stem cell specific characteristics.

To confirm the hematopoietic gene expression of these differentiated cells, the cells were first harvested using Trypsin $0.05 \%$ after 9 days and RNA was isolated using Trizol ${ }^{\circledR}$ reagent. We performed RT-PCR using primers for GATA-2, ${ }^{10}$ a known hematopoietic transcription factor, and for the hematopoietic cell related genes, HOXA9, ${ }^{19} \mathrm{IL}-7 \mathrm{R} \alpha$, and ATF $4 .{ }^{20}$ These cells expressed all these hematopoietic transcription factors GATA2, IL-7Ra, HOXA9 and ATF4 (Figure 5d).

\section{a}

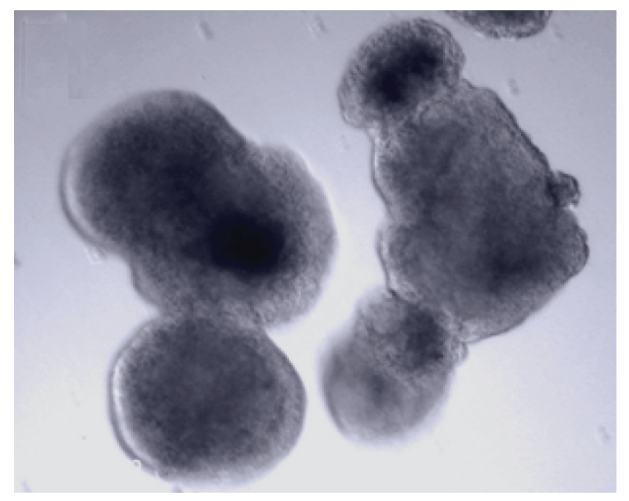

b

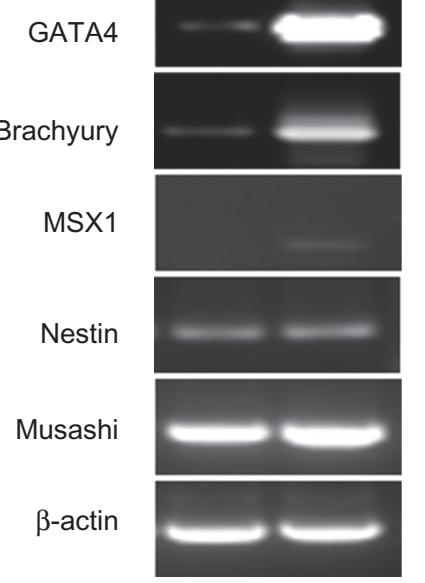

Figure 3 EBs of the $\mathrm{H} \mathbf{} 3$ cell line express all three embryonic germ layer markers: ES cells formed EBs (a) To study gene expression of these EBs, EBs were dismantled and cDNA prepared for PCR (b) Endoderm (GATA4), mesoderm (Brachyury, MSXI) and ectoderm (Nestin, Musashi) specific genes were detected, suggesting that the HI 3 cells are pluripotent and capable of forming tissues from all three germ layers. 

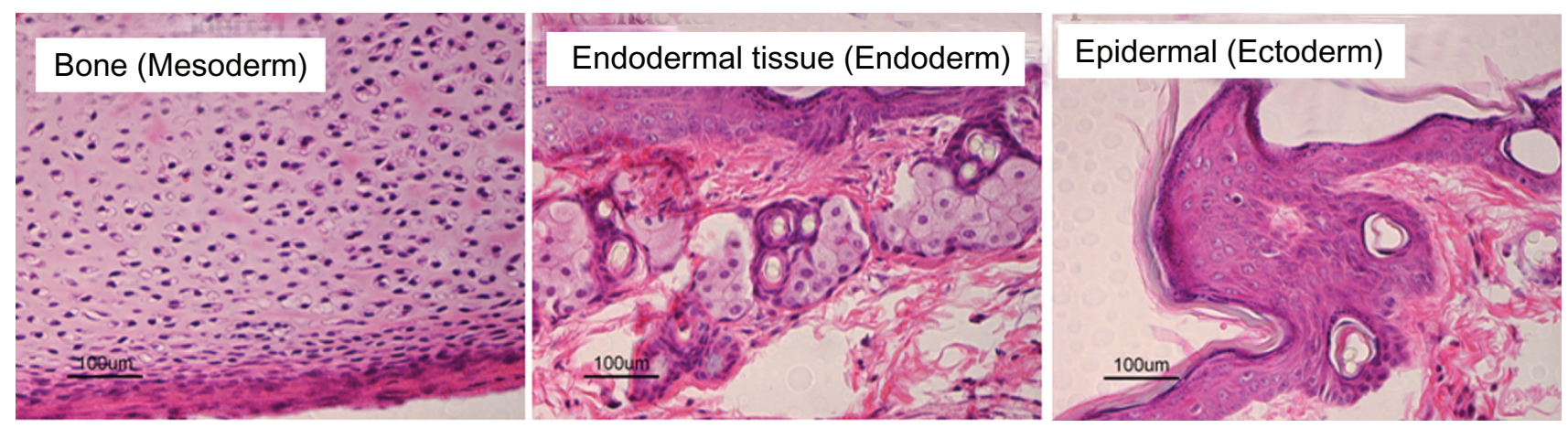

Figure 4 Human ES cells form teratomas: SCID mice were infused HI 3 cells subcutaneously and tumor formation monitored. After 9 weeks, teratiomas developed. Histological sections revealed tissues from all three germ layers.

To determine the phenotype of these differentiated cells, the cells were analyzed by flow cytometry using antibodies specific for hematopoietic stem cell markers. These data showed that progenitor cells derived from the $\mathrm{H} 13$ are $\mathrm{CD} 34^{+}$ (8\%-15\%), $\mathrm{CD}^{4} 4^{+} / \mathrm{CD} 43^{+}(2.7 \%)$ as well as $\mathrm{CD} 34^{+} / \mathrm{CD} 31^{+}$ HPCs (4.7\%) (Figure 6a). Typically, these HPCs expressed low levels of MHC class I antigens but no detectable class II antigens (HLA-DR). Peripheral blood lymphocytes were used as controls (Figure 6b).

\section{Discussion}

ES cells present an opportunity to study cell development, disease pathogenesis and establishment of new therapies. ${ }^{1}$
The ability of ES cells to form tissues of all three germ layers provides a new opportunity for deriving cells that potentially can be used to cure chronic degenerative diseases. However, to accomplish that goal, we need to establish efficient protocols that will allow us to derive the cell lineages of interest more efficiently. For the derivation of hematopoietic progenitor cells, several studies reported on improved and efficient embryoid body (EB)-mediated hematopoietic differentiation approaches. ${ }^{21,22}$ During EB development, stem cell factor (SCF), Flt-3 ligand, IL-3, IL-6, granulocyte colony-stimulation factor (G-CSF), and bone morphogenetic protein-4 (BMP-4) can promote hematopoietic differentiation of human embryonic a

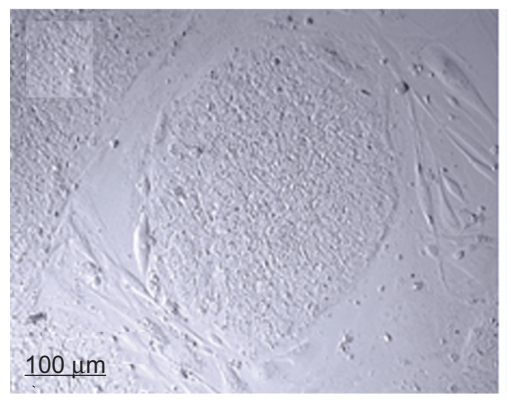

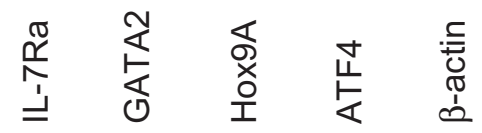

d

\section{b}
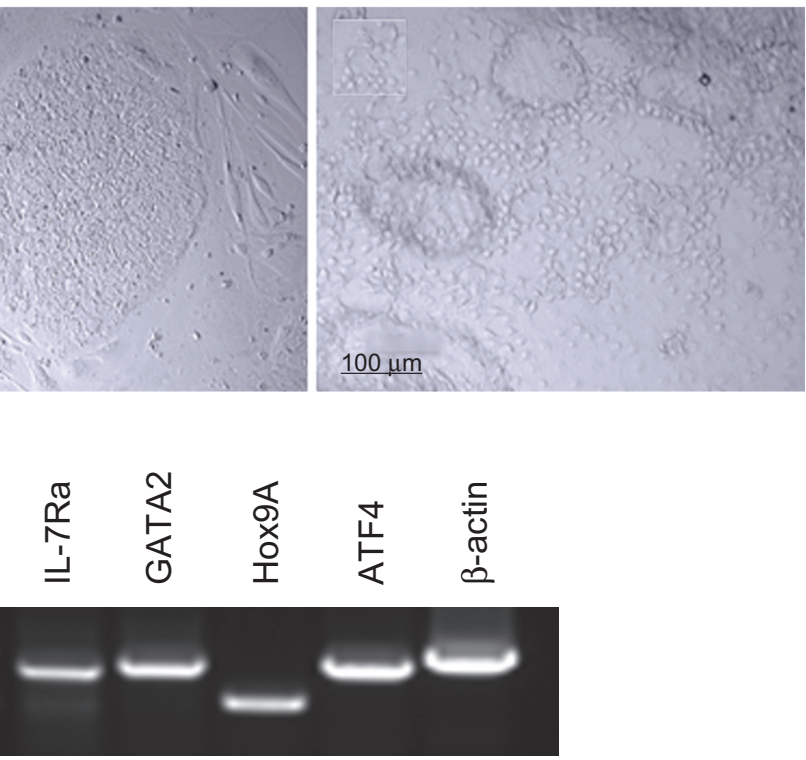

C
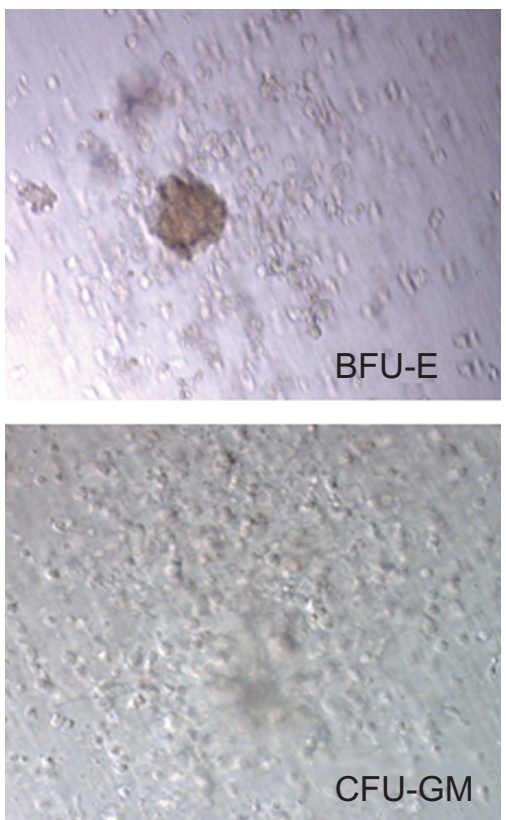

Figure 5 Hematopoietic cell differentiation of HI3 cells: ES cells (a) were co-cultured with the stromal cells OP9 (b). After 5-6 days, ES cells no longer appeared as clumps but rather as round cells suggesting their differentiation towards hematopoietic cells. (c) The CD34 $4^{+}$cells were cultured in methylcellulose media containing SCF, GM-CSF, IL-3 and Epo. After 18 days, BFU-E and CFU-GM were observed. (d) RT-PCR for IL-7Ra, GATA2, Hox9A, ATF4 and $\beta$-actin was performed. 

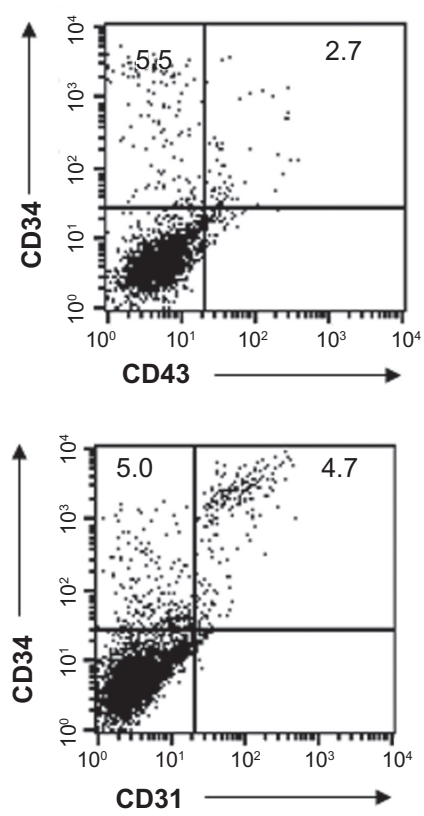

b

PBLs

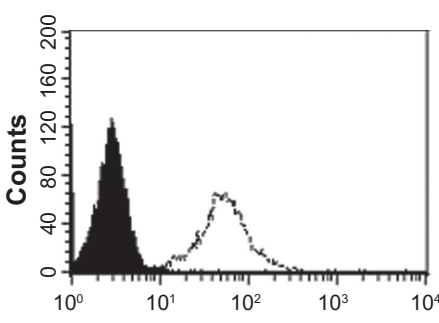

MHC I
ES cell derived HPCs

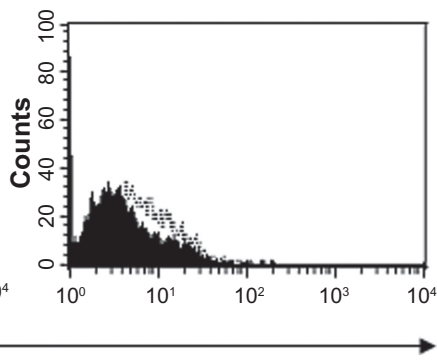

Class II

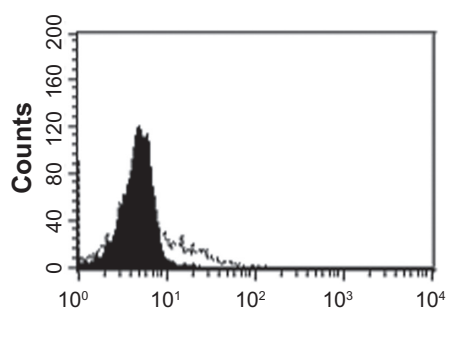

HLA-DR

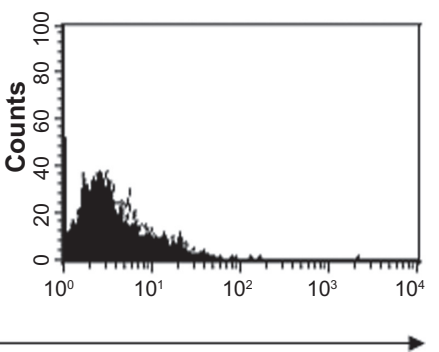

Figure 6 HI 3 derived HPCs poorly express MHC molecules: (a) The cells were harvested after 9 days and the stromal cells removed using an anti-CD29-PE antibody, which was specific for mouse stromal cells by immunomagnetic cell sorting. HI3-derived HPCs were phenotyped for $\mathrm{CD}^{2} 4^{+}$and $\mathrm{CD} 43^{+}$hematopoietic cell markers. (b) ES cell-derived HPCs showed low expression o MHC I and MHC II (HLA-DR). Filled histograms indicate isotype controls while broken lines indicate antibody stains. PBLs were used as positive controls.

stem cells. ${ }^{7,23}$ However, our own studies show that the impact of BMP4 alone on hematopoiesis of mouse ES cells is rather limited. ${ }^{14}$

The more commonly used approach is the use of stromal cell lines. Many reports have utilized stromal cells including fetal liver, murine bone marrow cell line S17, yolk sac endothelial cell lines and the OP9 cell line. ${ }^{9-12}$ According to more recently reported studies, co-culture of hES cells with primary stromal cells derived from the aorta gonado mesonephros (AGM) significantly enhances spontaneous hematopoietic cell differentiation of human cell lines. In particular, when hES cells were cultured with the AM20.1B4 cell line, an AGM cell line, hES cells more efficiently differentiated into HPCs. These HPCs when transplanted engrafted in immunocompromised NOD/LtSzScid IL2R $\gamma^{\text {null }}$ recipients. The mice engrafted with hES cell differentiated in the presence of AM20.1B4 cell line showed a significantly higher percentage of $\mathrm{CD} 45^{+}$cells $(16 \%)$ in the peripheral blood. ${ }^{13}$ This is rather low compared to the engraftment of mouse ES cell-derived HPCs. In our own lab, we have reported $80 \%-100 \%$ engraftment using mouse ES cell-derived HPCs. ${ }^{2}$ Thus, more needs to be done to accomplish higher yields of progenitors during human ES cell differentiation.
Ectopic expression of HOXB4 in hematopoietic cells has been shown to dramatically improve the survival of ES cell-derived hematopoietic progenitors in vivo. ${ }^{2,14,15,17}$ Consequently, this transcription factor has been widely used in mouse ES cells and mouse hematopoietic stem cells to expand hematopoietic cells. The impact of this homeobox transcription factor on human cells is still contoversial. ${ }^{24}$

Thus, there are a number of challenges ahead as we work to improve the existing protocols on hematopoiesis from human ES cells. Our data though show that ES-derived HPCs poorly express $\mathrm{MHC}$ antigens, which is important for their engraftment across MHC barriers. In future studies, we will examine whether these cells divide in vivo and are capable of multi-lineage mixed chimerism. These studies will advance our knowledge on whether ES-derived cells indeed have the potential for the derivation of HPCs capable of reconstituting the immune system. We also chose to use the H13 cell line that has not been used before for deriving hematopoietic cells in order to probe whether the ability to form hematopoietic progenitor cells is universal for all ES cell lines. Although the total yield of hematopoietic progenitors is still overall low, it is feasible to derive hematopoietic progenitors from $\mathrm{hES}$ cells. Future studies will probe the immunological characteristics of these cells further. 


\section{Acknowledgments}

This study would not have been possible without the generous grants from a VA Merit Review and grant RO1 HL073015, NIH/NHLBI.

\section{Authorship}

Eun-Mi Kim performed all experiments, analyzed data and wrote the manuscript. Nicholas Zavazava designed the research, wrote and revised the manuscript.

\section{References}

1. Thomson JA, Itskovitz-Eldor J, Shapiro SS, et al. Embryonic stem cell lines derived from human blastocysts. Science. 1998;282(5391): 1145-1147.

2. Chan KM, Bonde S, Klump H, Zavazava N. Hematopoiesis and immunity of HOXB4-transduced embryonic stem cell-derived hematopoietic progenitor cells. Blood. 2008;111(6):2953-2961.

3. Laflamme MA, Chen KY, Naumova AV, et al. Cardiomyocytes derived from human embryonic stem cells in pro-survival factors enhance function of infarcted rat hearts. Nat Biotechnol. 2007;25(9):1015-1024.

4. Bonde S, Chan KM, Zavazava N. ES-cell derived hematopoietic cells induce transplantation tolerance. PLoS One. 2008;3(9):e3212.

5. Yoo-Ott KA, Schiller H, Fandrich F, et al. Co-transplantation of donorderived hepatocytes induces long-term tolerance to cardiac allografts in a rat model. Transplantation. 2000;69(12):2538-2546.

6. Wang L, Li L, Shojaei F, Levac K, Cerdan C, Menendez P, et al. Endothelial and hematopoietic cell fate of human embryonic stem cells originates from primitive endothelium with hemangioblastic properties. Immunity. 2004;21(1):31-41.

7. Chadwick K, Wang L, Li L, et al. Cytokines and BMP-4 promote hematopoietic differentiation of human embryonic stem cells. Blood. 2003;102(3):906-915.

8. Martin CH, Woll PS, Ni Z, Zuniga-Pflucker JC, Kaufman DS. Differences in lymphocyte developmental potential between human embryonic stem cell and umbilical cord blood-derived hematopoietic progenitor cells. Blood. 2008;112(7):2730-2737.

9. Qiu C, Hanson E, Olivier E, et al. Differentiation of human embryonic stem cells into hematopoietic cells by coculture with human fetal liver cells recapitulates the globin switch that occurs early in development. Exp Hematol. 2005;33(12):1450-1458.

10. Kaufman DS, Hanson ET, Lewis RL, Auerbach R, Thomson JA. Hematopoietic colony-forming cells derived from human embryonic stem cells. Proc Natl Acad Sci U S A. 2001;98(19):10716-10721.
11. Vodyanik MA, Bork JA, Thomson JA, Slukvin II. Human embryonic stem cell-derived $\mathrm{CD}_{3} 4^{+}$cells: efficient production in the coculture with OP9 stromal cells and analysis of lymphohematopoietic potential. Blood. 2005;105(2):617-626.

12. Kitajima K, Tanaka M, Zheng J, Sakai-Ogawa E, Nakano T. In vitro differentiation of mouse embryonic stem cells to hematopoietic cells on an OP9 stromal cell monolayer. Methods Enzymol. 2003;365:72-83.

13. Ledran MH, Krassowska A, Armstrong L, et al. Efficient hematopoietic differentiation of human embryonic stem cells on stromal cells derived from hematopoietic niches. Cell Stem Cell. 2008;3(1):85-98.

14. Bonde S, Dowden AM, Chan KM, Tabayoyong WB, Zavazava N. HOXB4 but not BMP4 confers self-renewal properties to ES-derived hematopoietic progenitor cells. Transplantation. 2008;86(12): 1803-1809.

15. Helgason CD, Sauvageau G, Lawrence HJ, Largman C, Humphries RK. Overexpression of HOXB4 enhances the hematopoietic potential of embryonic stem cells differentiated in vitro. Blood. 1996;87(7): 2740-2749.

16. Pilat S, Carotta S, Schiedlmeier B, et al. HOXB4 enforces equivalent fates of ES-cell-derived and adult hematopoietic cells. Proc Natl Acad Sci US A. 2005;102(34):12101-12106.

17. Sauvageau G, Thorsteinsdottir U, Eaves CJ, et al. Overexpression of HOXB4 in hematopoietic cells causes the selective expansion of more primitive populations in vitro and in vivo. Genes Dev. 1995;9(14): 1753-1765.

18. Tian X, Morris JK, Linehan JL, Kaufman DS. Cytokine requirements differ for stroma and embryoid body-mediated hematopoiesis from human embryonic stem cells. Exp Hematol. 2004;32(10):1000-1009.

19. Yan J, Chen YX, Desmond A, et al. Cdx4 and menin co-regulate Hoxa9 expression in hematopoietic cells. PLoS One. 2006;1:e47.

20. Terskikh AV, Miyamoto T, Chang C, Diatchenko L, Weissman IL. Gene expression analysis of purified hematopoietic stem cells and committed progenitors. Blood. 2003;102(1):94-101.

21. Bauwens CL, Peerani R, Niebruegge S, et al. Control of human embryonic stem cell colony and aggregate size heterogeneity influences differentiation trajectories. Stem Cells. 2008;26(9):2300-2310.

22. Ng ES, Davis RP, Azzola L, Stanley EG, Elefanty AG. Forced aggregation of defined numbers of human embryonic stem cells into embryoid bodies fosters robust, reproducible hematopoietic differentiation. Blood. 2005;106(5):1601-1603.

23. Kennedy M, D’Souza SL, Lynch-Kattman M, Schwantz S, Keller G. Development of the hemangioblast defines the onset of hematopoiesis in human ES cell differentiation cultures. Blood. 2007;109(7): 2679-2687.

24. Wang L, Menendez P, Shojaei F, et al. Generation of hematopoietic repopulating cells from human embryonic stem cells independent of ectopic HOXB4 expression. J Exp Med. 2005;201(10):1603-1614.
Transplant Research and Risk Management

\section{Publish your work in this journal}

Transplant Research and Risk Management is an international, peerreviewed open access journal focusing on all aspects of transplantation and risk management to achieve optimal outcomes in the recipient improving survival and quality of life. The journal welcomes submitted papers covering original research, basic science, clinical studies,

\section{Dovepress}

reviews \& evaluations, guidelines, expert opinion and commentary, case reports and extended reports. The manuscript management system is completely online and includes a very quick and fair peer-review system, which is all easy to use. Visit http://www.dovepress.com/ testimonials.php to read real quotes from published authors. 